"This is the peer reviewed version of the following article: Occupational stress facing nurse academics-A mixed-methods systematic review Charanjit Singh RN, Bed, MMHIth Wendy Cross RN, PhD Ian Munro RN, PhD Debra Jackson RN, PhDFirst published: 19 December 2019, which has been published in final form at https://doi.org/10.1111/jocn.15150. This article may be used for non-commercial purposes in accordance with Wiley Terms and Conditions for Self-Archiving." 
Title Page: Occupational stress facing Nurse Academics - a mixed-methods systematic review.

\author{
Author details: \\ Mr. Charanjit SINGH, Lecturer, \\ (RN, B.Ed. M.M.Hlth). \\ Professor Wendy CROSS, Professor (R.N. PhD). \\ Dr. Ian MUNRO, Senior Lecturer, (R.N. PhD). \\ Professor Debra JACKSON, Professor, (R.N. PhD).
}

Author to whom correspondence about the manuscript should be sent:-

Mr. Charanjit Singh

School of Nursing \& Midwifery,

Faculty of Medicine, Nursing \& Health Sciences,

Monash University,

McMahons Road, Peninsula Campus,

Victoria, 3199

Australia.

Email Address: charanjit.singh@monash.edu

Telephone: +61 (03) 99044205

Facsimile: +61 (03) 99044655

\title{
Conflict of interest statement
}

"No conflict of interest has been declared by the author(s)".

\section{Funding Statement}

"This research received no specific grant from any funding agency in the public, commercial, or not-for-profit sectors."

\section{What does this paper contribute to the wider global community?}

- Changes to university work have been significant in the last 10 years. Whilst there is a body of literature about the stresses of academic life and the resultant psychological consequences, there has been no mix method systematic review undertaken that addresses the notion of occupational stress among nursing academics specifically. This systematic review adds to the existing knowledge of burnout among nursing academics.

- Globally, there is a paucity of literature on the prevalence and experience of burnout among nursing academics. The findings of this mix method systematic review identified several strategies that employing organisations should embrace to reduce occupational stress and burnout and enhance job satisfaction amongst nursing academics. 
Title: Occupational stress facing nurse academics: a mixed-methods systematic review

\section{Abstract}

Aim: To better understand occupational stress faced by nurse academics.

Methods: A mixed-method systematic review, following the Joanna Briggs Institute [JBI], (2014) process. Studies were assessed for quality and risk of bias by using standardised critical appraisal instruments from the Joanna Briggs Institute. In addition, processes and reporting were checked against the Equator guidelines. See Supplementary File 1.

Results: The review revealed that nursing academics do experience occupational stress, including burnout. Occupational stress for academic nurses is associated with various factors including work-life balance, workload issues, resources and support, and adapting to change. However, much of the literature focuses on nurses during the initial transition from clinical to academic environment, with rather less focus on established mid-to-late career nurse academics.

Discussion: Occupational stress and burnout are evident in the university academic workforce, adversely affecting the well-being of academic nurses, and the long-term sustainability of the academic nursing workforce. While there is considerable literature focusing on the novice academic nurse, particularly during the transition period, rather less is known about occupational stress among academic nurses across the career trajectory. Various strategies to deal with the negative consequences of occupational stress are identified, including: (a) quality mentors for novice and younger nursing academics (b) training in resilience building for novice academics (c) supporting collegial relationships and reducing bullying (d) assistance for professional development and research (e) better support and resources to overcome increasing workloads and (f) greater work-related empowerment to enhance job satisfaction.

Conclusion: There is a need for a broader whole-of-career research focus to more fully identify, explore and mitigate the occupational stressors that negatively affect the academic nurse workforce.

\section{Relevance to Clinical Practice:}

- A strong and resilient academic nurse workforce is essential for the sustainability of the profession.

- Organisations should review their work practices and provide greater work-related empowerment to reduce occupational stressors among nursing academics. 
KEYWORDS: literature review, systematic review, occupational stress, burnout, workload, resilience, job satisfaction, coping, work-life balance, nursing academics

\section{Introduction}

Internationally, the education of nurses is predominantly undertaken in the tertiary education sector. The nursing academic workforce is comprised of staff who perform a variety of roles including teaching, research and professional roles, some of which also have a base in clinical practice, such as with joint appointments between university and health facilities. In recent times, nursing academics have been subject to considerable stress associated with pressures on the university sector, including downsizing, government funding cuts, and more structured performance metrics. These and other factors have been associated with occupational stress influencing the experiences of the academic workforce (Bell, Rajendran \& Theiler, 2012; Shah, 2012).

Many writers including those in the United Kingdom (UK), United States of America (USA), Canada and Australia (Biron, Brun \& Ivers, 2008; Logan, Gallimore \& Jordan, 2015) have raised the increasing stress experienced by academics. Likewise, the consequences of occupational stress include decreased job satisfaction, mental ill health and low morale, and have been well reported in various countries and national surveys (Shaw, 2014; Watts \& Robertson, 2011; Winefield et al., 2003).

Selye (1956) first defined stress as the interaction between a stimulus and a response. Since then, it has been defined using various terms and whilst the wording differs, the meaning is essentially the same, depending upon how individuals perceive stress. Dolan et al., (1992) cited a number of factors that contributed to the experience of stress including inadequate human resources, incompetent unprofessional or unmotivated coworkers, interpersonal relationships, and bureaucratic political constraints.

Since the 1980's occupational stressors including burnout have been well documented and pose serious problems in various occupational settings including hospitals and universities (Bell, 2012; Blix, Cruise, Mitchell \& Blix, 2006; Chen, Haniff, Siau, Seet, Loh \& Jamil, 2014; Gui, Barriball, \& While 2009). Nursing academics like their other university colleagues are involved in a daily myriad of intense activities including faceto-face teaching, committee participation, interacting with students, and advocacy. 
Other responsibilities include counselling students, engaging in clinical practice, supervision of higher degree students, grant writing, preparing manuscripts, attending conferences, and undertaking research (Jackson, Peters, Andrew, Daly, Gray \& Halcomb, 2015).

It is well recognised that stress levels in academic institutions are high compared to many other populations, and stress has increased significantly over the last 15 years (Gui, Barriball, \& While 2009). In a recent study Aquino, Lee, Spawn, and BishopRoyse (2018) explored the impact of burnout, specifically on doctorate-nursing faculty (Ph.D. or DNP) intending to leave their academic position. They found that to address the nursing faculty shortage issue, it is essential to create supportive and positive working environments, provide additional emotional support and promote wellbeing (Aquino et al., 2018).

Lee, Miller, Kippenbrock, Rosen, and Emory (2017) explored job satisfaction and intent to stay in nursing academia. Their study highlights the importance of good leadership as the key to retaining nursing faculty members. In view of this, it could therefore be safely assumed that occupational stress is a prerequisite to burnout, and how this is manifested amongst nursing academics is important to explore. Importantly, the effects of occupational stress on nursing academic has an effect on the student learning outcomes and stress is a psychological factor that influences academic performance and welfare of nursing students (Sawatzky 1998).

In view of the findings in the literature, it is clear that nursing university academics are potential candidates for experiencing occupational stress due to their relationships and human interaction with large numbers of students, personnel and administrators. A preliminary search of the literature review on this topic revealed that there were both quantitative and qualitative studies that addressed occupational stress and burnout among academics (Gillespie,Walsh, Winefield,Dua \& Stough, 2010; Lackritz 2004; Roughton 2013; Smeltzer, et al., 2015; Wang \& Liesveld 2015; Watts \& Robertson 2011; Wieland \& Beitz 2015; Wyllie, et al., 2016; Yedidia et al., 2014). No recent systematic review on the occupational stressors facing nurse academics could be found. A comprehensive review of the evidence is required. 


\section{Aims and Methods}

The aim of this systematic review was to determine and synthesise the best and most recent available evidence regarding occupational stress faced by nurse academics. This mixed-methods systematic review is based on the PRISMA reporting guidelines (Moher, Liberati, Tetzlaff \& Altman, 2009). The design of the Joanna Briggs Institute (2014) approach for conducting systematic reviews of both quantitative and qualitative research was followed. The search methods, strategy, and outcomes are outlined in Figure 1. Following consultation with a health librarian, the following databases were searched: CINAHL, Embase, Medline, Psych INFO and Scopus. Search terms were Stress, Burnout, Job Satisfaction, Resilience, Coping, Workload, Hardiness and literature review; in combination using 'AND' and 'OR' Nursing Academic, Faculty Nursing, Nursing Lectures, and University/Staff. In order to maintain currency concerning present and future nursing academics and to avoid repetition of findings, publications were limited to 2003 to 2018.

Papers were limited to English language peer-reviewed empirical investigations of occupational stress in full-time nursing university academic staff. Papers not adopting a clear relationship to occupational stress among nursing academia were rejected. Both quantitative and qualitative research methodologies were included. The content and the quality of the published works were appraised using the JBI Assessment of methodological quality process (JBI Levels of Evidence, 2014).

A total of 6,212 papers were retrieved and after discarding 2,403 duplicate papers the remaining 3,809 papers were screened for relevance based on title. After screening for the relevant titles and abstracts a further 3,774 studies were removed. From this, 35 full text articles were identified for eligibility and for further detailed examination. A further 19 papers were discarded because they focused upon non-nursing academics, were commentaries and opinion papers and were not specific to the context of occupational stress. A final 16 papers (5 studies for qualitative synthesis and 11 studies for quantitative synthesis) met the inclusion criteria and were retained for this systematic review. The 16 studies were selected according to the inclusion criteria. The included studies were critically appraised for methodological quality using tools from the Joanna Briggs Institute ( PRISMA flow chart for search and screening process, Figure 1). 
The full text of papers identified were subjected to quality appraisal and were independently assessed for eligibility by the researcher and reviewed by two team members. Any disagreement between them over the eligibility of particular studies were resolved through discussion with a third reviewer. For the purposes of this paper there were no issues identified and there was no need for a third reviewer (Munn, Tufanaru \& Aromataris, 2014).

Quality appraisal was assessed by two members of the review team to avoid selection bias by using the Joanna Briggs Institute (JBI) critical Appraisal Tools (2014). The JBI QARI data extraction form for interpretive \& critical research was used to appraise the methodological quality for the five qualitative papers. This involved the synthesis of findings to generate a set of statements representing that aggregation, through gathering the findings rated according to their quality, and finally categorising these qualitative findings using thematic analysis allowing for similarity of meaning and interpretation (Popay et al., 2006). This process allowed for direct quotes and relevant data to be extracted from the findings of the five qualitative papers. The process involved coding the extracted data categorising it and then finally reducing into overarching themes. These narratives were then examined for 'conceptual overlaps' or subthemes (Popay et al., 2006). For the eleven quantitative papers included, the JBI Critical Appraisal Checklist for analytical cross sectional studies data extraction form was used.

Given the methods, instruments and findings of the included studies were heterogeneous; a meta-analysis was not undertaken for the eleven quantitative studies. A narrative approach was used to illustrate the findings of both the quantitative and qualitative studies to determine how these findings inform this systematic review. (Tables 1 and 2 provide an overview of the data extracted).

With regard to the 11 quantitative studies, multiple variations were identified, including multiple study designs and procedures (surveys and statistical analysis); and instruments, (Maslach Burnout Inventory (M.B.I.) National Survey of Nurse Educators Instrument (NLN), Conditions of Work Effectiveness Questionnaire (CWEQ), used to measure levels of stress, and different types of data collected. Meta-analysis was not applicable due to the heterogeneity in the methods of synthesis. In view of this, the second best approach, namely 
narrative synthesis is considered (Popay, Roberts, Sowden, Petticrew, Arai, Rodgers \& Duffy, 2006).

For the qualitative papers, the findings were pooled using the JBI-QARI tool. Data were aggregated in narrative form under the headings of the variables identified within the selected 16 studies in relation to the aims and context of the review (Popay et al. 2006). Conceptual overlaps were then combined from the identified sub-themes, such as attrition, retention, social bullying, empowerment, mentoring, explicating nursing academic experiences and factors responsible for occupational stress and burnout to form eight main themes (Table 1). Nevertheless, narrative synthesis cannot provide a clear weight of evidence with the possible bias of the conclusions of each study, therefore a table containing the characteristics of the studies is recommended to provide the extracted data and details (Munn., Tufanaru \& Aromataris, 2014). Table 1 and Table 2.

\section{Results}

A total of 16 studies were reviewed for the purposes of this mixed method systematic review, including 11 quantitative studies and 5 qualitative studies. There was a clear focus on novice academics with far less attention paid to occupational stress in nurse academics across the broader career trajectory. Notwithstanding this, the literature revealed nurse academics are facing a myriad of challenges in universities that could have an influence and impact upon the occupational stress experienced by nursing academic staff. In view of these reported experiences eight themes were identified including burnout, work-life balance, workload issues, resources \& support, age, adapting to change and resilience.

The evidence from the reviewed studies also identified several strategies to support academics including resilience building, help for professional development, mentoring and better support and resources to overcome increasing workloads.

The notion of burnout was addressed by three studies Kizilci, Erdogam \& Sozen, (2012) Sarmiento, Laschinger \& Iwasiw, (2004) and Yedidia, Chou, Brownlee, Flynn \& Tanner (2014). The first study by Kizilci, et al (2012), demonstrated that the relationship between nursing academic burnout and demographic data. They examined parameters such as age, marital status and academic positions, and these had an effect on the Emotional Exhaustion (EE), (Depersonalisation (DP) and Personal Achievement (PA) scores using the Turkish version of the Maslach Burnout Inventory (MBI). The 
study found that nursing academics aged 30 and below had lower Personal Accomplishment (PA) scores. However, no differences in age were identified on the Emotional Exhaustion (EE) and Depersonalisation (DP) scores on the MBI (Maslach \& Jackson, 1986). The findings infer that younger, less experienced and novice academics aged 30 and below probably felt less valued thus reflecting in their lower PA scores. This is well supported by Toker, (2011) who found that those aged 21-30 experienced higher levels of Depersonalisation (DP). In addition, "unpartnered" academics had higher Depersonalisation (DP) scores (Kizilci et al 2012). This infers the importance of the role of significant others in one's life to support and be available to discuss and debrief about the stresses and strains of daily academic work. There were no difference between Emotional Exhaustion (EE) and the Depersonalisation (DP) scores on academic positions. Weekly working hours had no correlation on the three dimensions of burnout scores. It is worth noting that all the participants were females and there could be a difference in gender scores comparing males to females. The study also shows the notion of occupational stress and burnout is rather complex and needs to be examined within each individual context and working environment (Kizilci et al., 2012).

Sarmiento, Laschinger \& Iwasiw, (2004) found that academics displayed a lower level of burnout when higher levels of empowerment and engagement were instilled by employers. The paper also highlighted important strategies that could be employed by nursing leaders and employers to enhance the level of personal job satisfaction. These could be achieved by education training, freeing lines of communication to develop collaborative and collegial relationships and instilling greater trust among colleagues. The findings demonstrated these strategies were associated with lower levels of burnout and greater work satisfaction (Sarmiento et al., 2004).

Yedidia et al., (2014), found that the major contributors to burnout were dissatisfaction with increasing workloads and perceived inflexibility with balancing work and family life. Their study surveyed $n=3,120$ full time nurse faculty members from 269 schools offering a degree program. The findings reveal a disturbing concern in that nearly four out of ten participants reported high levels of emotional exhaustion (EE), one major factor of burnout, leading to one-third expressing intent to leave nursing academia within 5 years. 
Likewise, material concerns played a prominent part, including salary and dissatisfaction with workloads and the lack of availability of teaching support, which led to emotional exhaustion (EE). The findings are well supported by other studies that highlight common stressors such as large class sizes, time constraints and pressures to undertake scholarship along with teaching responsibilities (Gui, 2009; Kizilci et al., 2012; McAllister et al., 2010; Roughton et al., 2013). The expectation of academics is to publish and disseminate research findings. This leads to added stress, which is a common phenomenon among nursing academics (Wilson et al., 2013). In addition, academics are frequently expected to be entrepreneurs and marketers. Regretfully, many novice academics may not have the skills required to fulfil such roles, which can prove to be disconcerting (Rothmann \& Barkhuizen, 2008). All of these expectations are occurring within a climate where resources have been reduced and this could lead to a toxic competitive nature within novice academics thus leading to a potential inadequate supply of nursing faculty and where many intend to leave. In a more recent study by Flynn \& Ironside (2018) the notion of burnout and its contributing factors among midlevel academic nurse leaders (such as assistant deans, associate deans) was explored. Their findings indicate that dissatisfaction with workload, work-life balance, and the long hours typically worked weekly increased the odds of burnout and was associated with the intention to leave.

Five studies addressed issues related to work life balance. Roughton (2013) identified that there needs to be greater work life balance with $31 \%$ of respondents highlighting this need. Smeltzer et al., (2015) found that doctoral programs in nursing faculty view their work-life balance favourably. There is however, a need to examine and consider the role of females due to the nature of their domestic roles in maintaining a work life balance. Efforts by faculty, needs to be reviewed in view of the increasing workload. They found that tenured staff and post-doctoral fellows had a better work life balance compared to non-tenured staff. Experienced writers and those with higher qualifications and more years of experience identified a better work life balance. This could be attributed to their experience and academic skills attained over the years. Interestingly, there was no significant relationship found across different sites. Tourangeau et al., (2013) found that more collegial relationship is needed to enhance work life balances. Yedidia et al., (2014) clearly demonstrated that one of the biggest factors responsible for burnout was the perceived inflexibility in balancing work and family life and 
dissatisfaction with work life balance. Westphal, Manorcha \& Chapin's (2016) study, equally supported this important aspect.

A number of studies identified various work load issues responsible for the level of dissatisfaction amongst nurse academics. Bittner and O’Connor, (2012) and Roughton, (2013) highlighted the importance of addressing workload issues in relation to enhancing greater job satisfaction. Smeltzer et al., (2015) argues the importance for greater involvement by faculty to carefully monitor the workload of less experienced faculty members. Perceived unreasonable workloads including high student numbers and insufficient support led to job dissatisfaction and greater chances of experiencing burnout Sarmiento et al., (2004). This finding echoes Yedidia et al., (2014) who identified dissatisfaction with workload issues was a major factor that contributed to burnout. Within the Australian context, McAllister et al., (2010) identified role overload, isolation, a non-validating culture, pace of change, and work role pressures as a challenge in meeting the needs of nursing academics. Various participants explained how the barriers and challenges act as impediments to the future workforce in nursing education (McAllister et al., 2010). Regarding workforce pressure one of the participants from McAllister's study stated,

"It can be stressful for lots of reasons; workload can be a problem, dealing with the requirements of registration bodies, academic bodies, trying to balance those for the benefit of students can be problematic” (Mc Allister et al., 2010. p10).

Whilst sessional teachers are needed to help continuing academic staff with teaching the academic programs, Peters et al., (2011) found that sessional teachers created an additional burden for the continuing staff. In most schools of nursing throughout Australia and the UK, due to the lack of resources, sessional teachers form a substantial element of the workforce. This is a global issue as more sessional staff are employed due to a shortage of nurse academics (Halcomb, Andrews, Peters, Jackson \& Salamonson, 2010).

One participant from Peter's et al., (2011) study explained,

"so the sessional staff, the problem that we've got in nursing, and I think that's been a problem for a good while, is that we've got people who are very good clinically, but they don't know how to teach-lacking skills and confidence”" (Peters et al., 2011, p 38). 
Bullying was construed as a serious workplace hazard with grave implications for retention and well-being of staff (Wieland \& Beitz, 2015). Many studies addressed the issues related to resources and support needed for nursing academics to progress in their roles and have greater work commitment. Factors included having good quality mentors (Gwyn, (2011), more carer development opportunities (Roughton, (2013) more supportive institutional policies and greater support for professional development (Wang \& Liesveld, 2015). Greater support and empowerment (Sarmiento et al., 2004) from faculty and feedback could help overcome the lack of confidence and uncertainty experienced by many newcomers in nursing academics (Wyllie et al., 2016) including providing more support for less experienced doctoral faculty members (Smeltzer, Sharts-Hopko, Cantrell, Heverly, Jenkinson \& Nthenge, 2015).

Likewise, supporting collegial relationships, having proper support and resources necessary for their work (Sarmiento et al., 2004), are necessary to enhance positive effects on employees, maintain retention rates (Tourangeau et al., 2013) and increase the availability of teaching support (Yedidia et al., 2014). Logan, Gallimore \& Jordan, (2015) found that more resources were needed to support novice nursing academics in their transition period from clinicians to academics, including mentorship to progress to postdoctoral research. Other important factors include more support for new academics where employing organisations need to embrace and support new employees and contribute to resilience building strategies when social bullying occurs ( McDermid et al., 2016; Wieland \& Beitz, 2015) and the development of standards for newly appointed sessional teachers (Peters et al., 2011).

Several studies identified barriers to job satisfaction and examined factors responsible for the retention of nursing academics (Bittner \& O'Connor 2012; Tourangeau et al., 2014). In relation to the barriers to job satisfaction, findings (Bittner \& O'Connor 2012; Tourangeau et al., 2014) indicated that $57 \%$ of the participants $(n=226)$ felt that a sense of accomplishment, coupled with autonomy in the role (50\%), having healthy relationships with colleagues $49.3 \%)$ and feeling safe at work (38.5\%) did contribute to greater job satisfaction (Bittner \& O'Connor 2012) including quality mentoring (Gwyn 2011). The need to have a better work life balance (Roughton, 2013), secured tenure (Smeltzer, 2015), have high levels of work-related empowerment (Sarmiento et al., 2004), greater engagement in assessing faculty quality of education and supporting collegial relationships (Tourangeau et al., 2013), have greater teaching support and 
realistic workloads (Yedidia et al., 2014), having greater remuneration in salary (Westphal, Manorcha \& Chapin, 2016) and elimination of social bullying (Wieland \& Beitz, 2015) were some of the major factors identified that contributed to greater job satisfaction in nursing academia. In turn, it is envisaged that by enhancing these factors it would reduce occupational stress and burnout.

Two studies (Kizilci et al., 2012; Yedidia et al., 2014) identified age as an influential factor and a predictor to burnout and intention to leave amongst nursing academics. Kizilci et al., (2012) found that younger academics aged 30 years and below reported a lower level of Personal Accomplishment (PA) on the MBI. Yedidia et al., (2014) identified that academics who were in the pre-retirement age group between 51-60 years had a higher intention to leave compared to their colleagues aged 50 years or younger. They found one fifth of those surveyed $(n=3,120)$, aged 50 years or younger intended to leave within 5 years of retirement age.

As previously stated, a number of papers focused on the transition into academic life and the issues around the changes needed to successfully negotiate this transition (Anderson 2009; Wyllie et al., 2016). There was evidence that newcomers to nursing academia were not sure what to expect (McDermid et al., 2013) and the lack of role clarity represented a source of additional stress. Logan, Gallimore and Jordan (2015) explored and compared the change of roles from a clinician to a nurse academic within the UK and Australia. The study highlighted the importance of support needed in postdoctoral study during this change of roles. Nurses moving from the clinical venue into academia often find this transition period a great challenge. One participant from Logan's study soon realised that there...

"was no sense of belonging, the lack of support and that' ongoing... I felt in a way I was left to fend for myself a lot of the time and you do survive and you get it done but it's a very stressful journey” (Logan et al., 2015. p. 597).

Logan's et al (2015) findings are well supported by other studies including Mc Dermid's et al., (2016) study which highlighted that many novice nurses struggle with role expectations, poor understanding of academic requirements leading to feelings of anxiety and isolation and with little understanding of the academic arena thus 
experiencing feelings of anxiety and isolation (McDermid et al., 2016). This point is well illustrated by a novice nurse from McDermid's et al., (2016) study who started her academic journey and shared her initial feelings...

"when I started, I didn't really know what I was supposed to be doing. There were so many different roles, not just teaching, but research and so many other things. It was daunting” (Mc Dermid et al., 2016, p31).

For some unfortunately, these novice academics were unable to make this shift and adjustments. They found the stresses too overbearing and made the decision to leave and return to clinical nursing.

"back to nursing because I don't care how hard I work at that bedside for that 12 hours when I go home it's over" (Mc Dermid et al., 2013, p50).

Anderson (2009) presented a metaphor where novice nurse academics found themselves overwhelmed in their new academic role, which they identified as 'drowning', or 'treading water' (pg. 204). For many clinicians moving into academia found the work environment less cohesive and lacking in teamwork, but had more autonomy and academic freedom. Some novice clinicians found it isolating, scary, others found it enabling (Logan et al., 2015). The added stress and pressure for the novice academics to publish and undertake research is well articulated (Coates \& Goedegebuure, 2012; Wyllie, Di Giacomo, Jackson \& Davidson, 2016) and if these concerns are not addressed it means that capable and good quality novice academics could be lost along the transition to progression (Logan et al., 2015). These results support other studies that examine the challenges faced by novice nurse academics (Cleary et al., 2010; McDermid et al., 2016; Wyllie et al., 2016).

Four studies explored the importance of developing resilience in the workplace. McDermid, et al., (2016), focused upon the importance of teaching appropriate resilience strategies to novice nursing academics to cope with the transition of their new role. Strategies and themes included being supportive, forming collegial relationships, embracing positivity, and utilising reflection and transformative growth to develop resilience.

Wieland and Beitz (2015) explored the notion of resilience building in response to social bullying, and this has serious implications for retention and staff well-being. 
Wieland and Beitz's (2015) study reflected the concerns of previous research (Cleary et al., 2010; Goldberg et al., 2013), which found bullying within academic nurse professionals and nursing profession (Cleary et al., 2010) leading to turnover as a warning sign, but can be offset by resilience strategies. This study identified resilience strategies including having protective factors like family and collegial support, being engaged in social activities, educating and raising one's own level of self-awareness in relation to workplace bullying.

Given that most nursing academics are females, paradoxically, Weiland and Beitz, (2015) found that gender did not a play a role in the bulling process. Bullied staff considered planning a new job as a form of resilience building. This clearly has serious implications for recruitment, retention and well-being. Yildrim and Cam (2012) reflect the sentiments in their study and highlighted the importance of the temperament feature of persistence for greater job involvement and motivation.

McDermid and colleagues (2016) argue that developing supportive relationships provides insight into the mentoring process. Secondly, it embraces positivity allowing them to face adversity and challenges within their new role. Lastly, McDermid et al., (2016) see reflection as an integral part of personal transformative growth. This is well confirmed by other writers. There were participants who were able to reflect and "bounce back" and learn from their experiences, an attribute considered as crucial and a key component in defining the concept of resilience (Hart \& Chesnay, 2012).

McDermid et al's (2016) participant clearly demonstrates the notion of embracing resilience and is illustrated in the following quote,

"I look back and I remember being terrified. I got sent the class outline a couple of days before...I stood in front of this classroom of students thinking 'I can't' do this; I'm a nurse not a teacher! ...but you know as nurses we tend to just roll with the punches and we just sort of go in and do it... and I did it”" (McDermid et al., 2016. p33).

In spite of the adversities many novice nurses, managed to developed strategies that build resilience. This instilled confidence, self-esteem self-efficacy, trust and connectedness including enhancing their quality of life which in turn could lead to retention (Hart et al., 2012). 
In trying to cope with overwhelming demands and workload, many novice academics need to be career- resilient (Wyllie et al., 2016). This can be achieved by embodying resilience and a few strategies suggested include being dedicated to the notion of continuous learning; keeping pace with the changes, and taking responsibility by forming meaningful relationships and feeling supported by mentors (Wyllie et al., 2016). Building resilience enhances quality of life and assists in workforce retention (Hart et al., 2012).

Mentoring is an important aspect in developing resilience and helping novice nurse academics develop a career path (Mc Dermid et al., 2016). These findings are well supported in the literature and considered crucial as contributory factors in developing resilience (Mc Dermid et al., 2016; McDonald et al., 2015).

Garcia-Dia et al., (2013) add to the debate claiming that a positive mentoring relationship fosters resilience and improved outcomes. Wyllie, Di Giacomo, Jackson, Davidson \& Phillips (2016), review offers collective insight into novice academic nurses. They found three attributes namely, a willingness to adapt to change, an intention to pursue support and embodying resilience for novice nurse academics to be successful in their career paths. They also recommend novice nurse academics be aware of their own skills, strengths and weakness. Likewise, management needs to work closely with the novice nurses and get them exposed early to appropriate careers developing situations (Wyllie et al., 2016). This partnership in resilience building is crucial for the benefit of the novice nurse academic and faculty.

\section{Discussion}

The aim of this systematic review was to determine and synthesise the best and most recent available evidence regarding occupational stress faced by nurse academics. A range of occupational stressors including burnout are identified as problematic in nursing academia. There is considerable consensus in the literature pertaining to causative factors of occupational stress and burnout. Generally, it is linked to the work environment and the individual's personality impacting on their psychological or physical well-being (Khamisa, Peltzer \& Oldenburg, 2013). Occupational stress and burnout affects all professions that involve human interaction, including education. It can be best described as how the individual perceives and reacts to individual work related demands and the ability to cope with these demands. 
This systematic review collates views and develops insight into contributory factors leading to occupational stress and burnout. The findings uncovered the experiences of novice and nurse academics facing a myriad of challenges that could contribute, influence and impact upon the occupational stress and burnout experienced by nursing academic staff. Some important factors contributing to burnout were issues including increasing workload, barriers to job satisfaction, a lack of sense of belonging, not being autonomous, poor relationships with colleagues due to the competitive work environment. Dissatisfaction with workload, a non-caring culture, a rapid transformative environment, lack of teaching support, social bullying, isolation and an inflexible work life balance are noted factors. Younger novice and less experienced nurse academics were more vulnerable to occupational stress and burnout. Some of the identified factors were a lack of professional autonomy, high leader role expectations, toxic organisational climate, and role ambiguity leading to conflict (Gui et al., 2009; Shah, 2012).

In addition to traditional roles of teaching, research and service, academics are frequently expected to be entrepreneurial. However, Rothman \& Barkhuizen, (2008) argue they may not have the required skills to fulfil such roles leading to distress. In an environment where resources are reducing coupled with an inadequate supply of nursing faculty personal leads to occupational stress where individuals question their continuing role.

Our review of the literature suggests that many nursing academics experience harmful work environments. To overcome this "toxicity" and to minimise these attrition rates and to maximise retention a number of strategies have been suggested, such as having quality experienced mentors, support for professional development, and inclusive friendly cultures. Employing organisations need to be less hierarchical in their approach, embrace and support new employees and contribute to resilience building strategies especially during the transitional phase for academic nurses. If the present situation is not addressed and changed, it is highly likely that the persistent daily demands experienced by nursing academics will affect the quality of their personal and work life and lead to adverse consequences, including burnout and greater intention to quit. There were a number of limitations in the preparation of this systematic review. 
Papers were limited to English language and full text. Only peer-reviewed empirical investigations of occupational stress in full-time nursing university academic staff were accepted. Generalisability of the findings to other academics within university different sectors and faculties might be limited given that only studies examined were concerning nurse academics.

\section{Conclusion}

The collective findings from this review offers valuable insight into the present daily challenges that nursing academics face to overcome the reported dissatisfaction and occupational stress leading to burnout. In spite of being one of the youngest fraternities within the University environment, it is both alarming and surprising to note that nursing academia is a 'toxic' work environment with many organisational stressors. There are a number of important implications that need to be addressed by the employing organisations to change the environment so that more nurses and clinicians thinking of a career in academia could be encouraged with a clear direction and proper support in order to overcome the risk of experiencing occupational stress and burnout. There needs to be a more open and candid dialogue between the employing organisation and nursing academics that express their daily frustrations and challenges. To date, there has been a focus on occupational stressors facing novice nurse academics during the transition to academic life. Further research taking a broader, whole of career approach is needed. These factors need to be considered by employing authorities when instituting any organisational changes to reduce the level of occupational stress amongst nursing academics. Kizicli et al., (2012) suggests that nurse academics be examined for other variants of occupational stress and burnout in view of the complex nature of the occupational stress and burnout.

\section{Relevance to Clinical Practice}

Academic Nurses carry multiple responsibilities including teaching, counselling to students, committee membership in their organizations (Jackson et al., 2015). In view of these findings, this mixed method systematic review study have direct implications upon how the well-being of nursing academics could influence and directly affect clinical practice and in turn the learning needs of nursing students of their faculty. It is 
therefore reasonable to assume that Nursing Academics who experience occupational stress may not be able to perform well in their daily roles thus affecting the learning needs and outcomes of their students.

The findings of this study identified several strategies that employing organisations should embrace and be proactive to deal with the negative consequences of occupational stress. These include (a) having experienced mentors (b) promote resilience building (c) having supportive collegial relationships (d) supporting professional development and research and (e) resources for increasing workloads. This study has been able to integrate the data extracted from the quantitative and qualitative studies and the single systematic review to gain a collective insight and understanding of antecedents contributing to occupational stress among nursing academics. 


\section{References:}

Anderson, J.K. (2009). The work-role transition of expert clinician to novice academic educator. Journal of Nursing Education 48 (4), 203 -208.

Aquino, E., Lee Y-M., Spawn, N. \& Bishop Royse, J. (2018). The impact of burnout on doctorate nursing faculty's intent to leave their academic position: A descriptive survey research design. Nurse Education Today, Vol 69, Oct, pp35-40. Doi.org/1016/j.nedt.2018.06.027

Bittner, N.P \& O'Connor, M. (2012). Focus on retention: Identifying barriers to nurse faculty satisfaction. Nursing Education Perspectives, 33(4):251-254.

Bell, A.S., Rajendran, D., \& Theiler, S. (2012). Job stress, well-being and work-life balance of academics. Electronic Journal of Applied Psychology. 8(1): 25-37.

Biron, C., Brun, J-P., \& Ivers, H. (2008). "Extent and sources of occupational stress in university staff." Work, 30(4): 511-522.

Blix, A.G.,Cruise, R.J., Mitchell, B.N., \& Blix, G.G. (2006). Occupational stress among university teachers, Educational Research, doi.org/10.1080/0013188940360205, 36 (2), 157-169

Cleary M., Hunt, G.E., \& Horsfall, J. (2010). Identifying and addressing bullying in nursing. Issues in Mental Health Nursing, 31 (5): 331-335.

Coates, H., \& Goedegebuure, L. (2012). Recasting the academic workforce why the attractiveness of the academic profession need to be increased and eight possible strategies for how to go about this from an Australian perspective. High Education. 64 (6), 875889.

Dolan, S., Van Ameringen M.R., Corbin, S. \& Arsenault, A. (1992). Lack of professional latitude and role problems as correlates of propensity to quit amongst nursing staff. Journal of Advanced Nursing 17, pp 1455-9.

Flynn, L \& Ironside, P.M. (2018). Burnout and its contributing factors among midlevel academic nurse leaders. Journal of Nursing Education. 2018; 57(1):28-34 doi. https://org.10.3928/01484834-20180102-06

Garcia-Dia, M.J., Di Napoli, J.M., Jakubowski, R. \& O'Flaherty, D. (2013). Concept analysis: resilience, Achieves of Psychiatric Nursing, 264-270.

Gillespie, N.A., Walsh, M., Winefield, A., Dua., J, \& Stough, C. (2001). Occupational Stress in Universities: Staff perceptions of the causes, consequences and moderators of stress. Work \& Stress: An International Journal of Work Health \& Organisations. 15(1) Doi: 10:1080/02678370117944.

Goldberg E., Beitz, J., Wieland, D., Levine, C. (2013). Social bullying in nursing academia. Nursing Education, 38 (5); 1-7. 
Gui, L., Barriball, K.L., \& While, A. E. (2009). Job Satisfaction of nurse teachers: a literature review. Part 1: Measurement, levels and components. Nurse Education Today, 29(5) 469-76. DOI: http://dx.doi.org/10.1016/j.nedt.2008.11.003.

Gwyn, P.G. (2011). 'The quality of mentoring relationship's impact on the occupational commitment of nursing faculty. Journal of Professional Nursing, 27(5): 292-298.

Halcomb, E.J., Andrews, S., Peters, K., Jackson, D., \& Salamonson, Y. (2010). Casualisation of the teaching workforce: Implications for nursing education. Nurse Education Today, 30, 528 -532.

Hart, P., Brannan, J, \& Chesnay, M. (2012). Resilience in nurses: an integrative review. Journal Nursing Management. (on-line).

Jackson, D., Peters, K., Andrew, S., Daly, J., Gray, J., \& Halcomb, E. (2015). Walking alongside: a qualitative study of the experiences and perceptions of academic nurse mentors supporting early career nurse academics. Contemporary Nurse, 1-14.

Joanna Briggs Institute. (2014). Joanna Briggs Institute Reviewers' Manual: 2014 edition. Retrieved from http://joannabriggs.org/assets/docs/sumari/Reviewers Manual-2014.pdf

Khamisa N, Peltzer K., \& Oldenburg, B. (2013). Burnout in relation to specific contributing factors and health outcomes among nurses: A systematic review, International Journal of Environmental Research and Public Health, 10:2214-40.

Kizilci, S., Erdogam, V., \& Emie Sozen, M.S. (2012). The Influence of selected personality and workplace features on Burnout among Nurse Academics. TOJET. The Turkish Online.

Lackritz, J.R. (2004). Exploring burnout among university faculty: incidence, performance, and demographic issues. Teacher and Teacher Education 20, 713-729.

Lee, P., Miller, M.T., Kippenbrock, T.A., Rosen, C. \& Emory J. (2017). College nursing faculty job satisfaction and retention: A national perspective. Journal of Professional Nursing. Vol 33, pp 261-266. Doi 10.1016/j/profnurs.2017.01.001

Logan, P.A. Gallimore D., \& Jordan, S. (2015). Transition from clinician to academic: an interview study of the experiences of UK and Australian Registered Nurses. Journal of Advanced Nursing, 72(3):593-604.

Maslach, C., \& Jackson, S.E. (1986). Maslach burnout inventory research edition. 2nd edn. Palo Alto, CA: Consulting Psychologists Press.

McAllister, M., Madsen W., Godden J., Greenhil, J \& Reed, R. (2010). Teaching nursing's history: A National survey of Australian Schools of Nursing, (2007 -2008), Nurse Education Today, 30(4):370-5. doi: 10.1016/j.nedt.2009.09.010 
McDermid, F., Peters, K., Daly, J. \& Jackson, D. (2013). 'I thought I was just going to teach', Stories of new nurse academics on transitioning from sessional teaching to continuing academic positions. Contemporary Nurse, 45(1), 46-55.

McDermid, F., Peters, K., Daly, J., \& Jackson, D. (2016). Developing resilience: Stories from novice nurse academics." Nurse Education Today, 38:29-35.

McDonald, G., Jackson, D., Vickers, M., \& Wilkes, L. (2015). Surviving workplace adversity: a qualitative study of nurses and midwives and their strategies to increase personal resilience. Journal of Nursing Management, 1-9.

Moher D, Liberati A, Tetzlaff J, \& Altman DG. The PRISMA Group (2009) Preferred Reporting Items for Systematic Reviews and Meta-Analysis: The PRISMA statement PLoS Med 6 (7) e1000097.https// doi 10.1371/journal. pmed. 1000097.

Munn, Z., Tufanaru, C., \& Aromataris, E. (2014). Data Extraction and Synthesis The steps following study selection in a systematic review. American Journal of Nursing, 114(7), 49-54. doi:10.1097/01.NAJ.0000451683.66447.89

Peters, K., Jackson, D., Andrew, S., Halcomb, E.J., \& Salamonson, Y. (2011). Burden versus benefit: Continuing nurse academics experiences of working with sessional teachers. Contemporary Nurse, 38 (1-2): 35-44.

Popay, J., Roberts, H., Sowden, A., Petticrew, M., Arai, L., Rodgers, M., \& Duffy, S. (2006). Guidance on the conduct of narrative synthesis in systematic reviews. A product from the ESRC methods programme. Lancaster: Institute of Health Research.

Rothmann, S., \& Barkhuizen, N. (2008). Burnout of academic staff in South African higher education institutions. South African Journal of Higher Education, 22 (2), 439-456.

Roughton, S.E. (2013). Nursing Faculty Characteristics and Perceptions Predicting Intent to Leave. Nursing Education Perspectives: August 2013, 34,(4), 217-225. doi: http://dx.doi.org/10.5480/1536-5026-34.4.217.

Sawatsky J.V. (1998). Understanding nursing students 'stress: a proposed framework Nurse Education Today, Volume 18, Issue 2, pp 108-115.

Sarmiento, T. P., Laschinger, H. K. S., \& Iwasiw, C. (2004). Nurse educators' workplace empowerment, burnout, and job satisfaction: testing Kanter's theory. Journal of Advanced Nursing, 46(2), 134-143.

Selye, H. (1956). The Stress of Life. New York: McGraw-Hill.Shah, M. (2012). Renewing strategic planning in universities at a time of uncertainty. Perspectives: Policy and Practice in Higher Education, 1-6. doi: 10.1080/13603108.2012.679753. 
Shah, M. (2012). Renewing strategic planning in universities at a time of uncertainty. Perspectives: Policy and Practice in Higher Education, 1-6. doi: 10.1080/13603108.2012.679753.

Shaw C. (2014). Overworked and isolated - work pressure fuels mental illness in academia. https//www.the guardian.com

Smeltzer, S.C., Sharts-Hopko, N.C., Cantrell, M.A., Heverly., M.A., Jenkinson, A., and Nthenge, S. (2015). Work-life balance of nursing faculty in research and practicefocused doctoral programs. Nursing Outlook, 63 (6), 621-631.

Toker, B. (2011). Burnout among university academicians: an empirical study on the universities of Turkey. Doğuş Üniversitesi Dergisi, 12 (1), 114-127.

Tourangeau, A. E., Saari, M., Patterson, E., Thomson, H., Ferron, E. M., Widger, K., \& MacMillan. K. (2013). Work, work environments and other factors influencing nurse faculty intention to remain employed. A cross-sectional study. Nurse Education Today: 34 (6) 940 -7 doi: 10.1016/j.nedt.2013.10010.

Wang, Y., \& Liesveld, J. (2015). "Exploring Job Satisfaction of Nursing Faculty: Theoretical Approaches." Journal of Professional Nursing, 31(6): 482-492.

Watts, J. \& Robertson, N. (2011). 'Burnout in university teaching staff: a systematic literature review' Educational Research, 53, 1, 33-50.

Westphal, J., Manorcha, S., \& Chapin, T. (2016). "A Pilot Study to Explore Nurse Educator Workforce Issues." Nursing Education Perspectives, 37(3): 171-173.

Wieland, D. and Beitz, J.M. (2015). "Resilience to Social Bullying in Academia: A Phenomenological Study." Nurse Educator, 40(6): 289-293.

Wilson, A., Sharrad, S., Rasmussen, P., \& Kernick, J. (2013). Publish or perish: Ensuring longevity in nursing education-evaluation of a strategy to engage academics, students, and clinicians in publication activity. Journal of Professional Nursing, 29(4), 210-216. doi:10.1016/j.profnurs.2012.04.024

Winefield, A.H., Gillespie, N., Stough, C., Dua, J., Hapuarachchi, J., and Boyd, C. (2003). "Occupational Stress in Australian University Staff: Results from a National Survey" International Journal of Stress Management, 10 (1),51-63.Winter R., Tony T., \& James S. (2000). Trouble at Mill: quality of academic work life issues within a comprehensive Australian university. Studies in Higher Education, 25(3).

Wyllie, W., DiGiacomo. M; Jackson, D; Davidson, \& Phillips, J. (2016). Acknowledging attributes that enable the career academic nurse to thrive in the tertiary education sector: A qualitative systematic review. Nurse Education Today, 45 (2016) 212-218.

Yedidia, M.J., Chou, J., Brownlee, S.J., Flynn, L., \& Tanner, C.A. (2014). Association of Faculty Perceptions of Work-Life with Emotional Exhaustion and Intent to Leave 
Academic Nursing: Report on a National Survey of Nurse Faculty. Journal of Nursing Education 53(10):569-579. DOI: 10.3928/01484834-20140922-0.

Yildrim, S., \& Cam, O. (2012). Nursing academicians' attitudes towards work life and their personality traits. Journal of Psychiatric and Mental Health, 19 (8), 709-714, DOI:10.1111/j.1365-2850.2011.01835.x.

\section{Summary Box. What does this paper contribute to the wider global community?}

- Changes to university work have been significant in the last 10 years. Whilst there is a body of literature about the stresses of academic life and the resultant psychological consequences, there has been no mixed method systematic review undertaken that addresses the notion of occupational stress and burnout specifically among nursing academics. This systematic review adds to the existing knowledge of occupational stress among nursing academics. 